\title{
Distribution of Glucose Transporter Messenger RNA Transcripts in Tissues of Rat and Man
}

\author{
Jeffrey S. Flier, ${ }^{\star *}$ Mike Mueckler," Anthony L. McCall," and Harvey F. Lodish*" \\ *The Whitehead Institute for Biomedical Research, 'Department of Biology, Massachusetts Institute of Technology, \\ Cambridge, Massachusetts 02139; ${ }^{\ddagger}$ The Charles A. Dana Research Institute and the Harvard-Thorndike Laboratory \\ of Beth Israel Hospital, Department of Medicine, Beth Isreal Hospital and Harvard Medical School, Boston, Massachusetts 02215 ; \\ ${ }^{8}$ Department of Cell Biology and Physiology, Washington University School of Medicine, St. Louis, Missouri 63110; \\ "Evans Memorial Department of Medicine and Division of Diabetes and Metabolism, University. Hospital, \\ and Department of Physiology, Boston University Medical Center, Boston, Massachusetts 02118
}

\begin{abstract}
We used the complementary DNA for the human hepatoma Hep G2 glucose transporter to determine the distribution of glucose transporter messenger RNA (mRNA) in rat and human tissues. Under stringent hybridization conditions, a single 2.8-kilobase (kb) transcript is seen in all rat and human tissues examined. The mRNA is most abundant in brain, and is especially enriched in the brain microvascular fraction.

The mRNA abundance in rat muscle and fat is $5 \%$ that in brain. Rat liver (both adult and fetal) and human liver have very little 2.8-kb mRNA, but it is abundant in cultured human fibroblasts and EB virus-transformed lymphoblasts. The same size mRNA is present in leg muscle of two type II diabetic patients.

A very homologous glucose transporter mRNA is expressed in both insulin-sensitive and -insensitive tissues of rat and man. Hepatocytes, which have abundant glucose transport, may express a homologous but nonidentical glucose transporter.
\end{abstract}

\section{Introduction}

Glucose homeostasis in mammals requires both the uptake of extracellular glucose into tissues such as muscle, fat, and liver as well as the mobilization of glucose from hepatocytes into the circulation. The molecular basis for cellular glucose transport has been intensively investigated, and this process appears to be mediated by one or more glucose-specific transport proteins (1). Although glucose transport has been studied in many tissues, the best characterized glucose transport protein is the facilitated diffusion glucose carrier of the human erythrocyte, a 55,000-kD integral membrane glycoprotein (2-4). Recently, Mueckler et al. used a rabbit antibody directed against this protein to obtain a complementary DNA (cDNA) clone for the glucose transporter

Address reprint requests to Dr. Flier, Diabetes Unit, Beth Israel Hospital, 330 Brookline Ave., Boston, MA 02215. 1986.

Received for publication $18 \mathrm{July} 1986$ and in revised form 1 October

J. Clin. Invest.

(c) The American Society for Clinical Investigation, Inc.

$0021-9738 / 87 / 02 / 0657 / 05 \$ \$ 1.00$

Volume 79, February 1987, 657-661 from a lambda gt-11 cDNA library prepared from the Hep-G2 human hepatoma cell line (5). The amino acid sequence deduced from the cDNA clone agreed with the partial sequences available for the erythrocyte transporter (5), suggesting that human erythrocytes and hepatocytes, two tissues in which glucose transport is insensitive to insulin, may have the same transporter species. In contrast to erythrocytes and hepatocytes, the rate of glucose transport in tissues such as muscle (6) and fat (7) is strongly influenced by insulin. It is unknown, however, whether differences between tissues in the sensitivity of their glucose transport systems to insulin are due, entirely or in part, to differences in the structure of the glucose transporter. As an initial approach to this question, we undertook to examine the tissue-specific expression of mRNA encoding or homologous to the Hep-G2 glucose transporter in various tissues of rat and man.

\section{Methods}

RNA isolation. RNA was isolated from fresh tissue or cultured cells by the guanadinium thiocyanate- $\mathrm{CsCl}$ technique (8). Where indicated, polyadenylated RNA was obtained by oligo deoxythymidylate cellulose chromatography (9). Isolated rat hepatocytes were prepared by the collagenase technique (10), and calf brain microvessels were prepared as described by McCall et al. (11).

Northern gels. RNA was electrophoresed on $1.2 \%$ formaldehyde agarose gels (12), blotted and fixed onto nylon filters, and then hybridized to either CDNA or antisense RNA probes. The cDNA probe is a mixture of two [ $\left.{ }^{32} \mathrm{P}\right]$ nick-translated glucose transporter cDNA fragments. The two fragments are 450 base pair (pGT25S) and 2,400 base pair (pGT25L) Eco RI fragments that together contain nearly a full-length copy of the mRNA (5). Nick translation was performed using a nick translation kit (Amersham Corp., Arlington Heights, IL) according to instructions specified by the manufacturer.

Hybridization with the cDNA probe was carried out at $42^{\circ} \mathrm{C}$ in a solution comprised of $50 \%$ formamide, $5 \times \operatorname{SSPE}(0.9 \mathrm{M} \mathrm{NaCl}, 5 \mathrm{mM}$ EDTA, and $50 \mathrm{mM} \mathrm{NaH} \mathrm{PO}_{4}, \mathrm{pH} 7.4$ ), $0.2 \%$ sodium dodecyl sulfate, $0.1 \%$ each of bovine serum albumin, polyvinylpyrolidine, and Ficoll, and denatured, sheared salmon sperm DNA $(200 \mu \mathrm{g} / \mathrm{ml})$. The probe was included at $10^{7} \mathrm{cpm} / \mathrm{ml}$. After being washed in $0.1 \times \mathrm{SSPE}$ at $50^{\circ} \mathrm{C}$ (three washes of $30 \mathrm{~min}$ each), the blot was exposed to Kodak XAR-5 film at $-70^{\circ} \mathrm{C}$ for varying time periods as indicated in figure legends (intensifying screen, Cronex Lightening Plus, DuPont, Wilmington, DE).

$R N A$ probe. The Hep-G2 glucose transporter cDNA was subcloned into the Bam HI site of the pGEM plasmid (Promega Biotech, Madison, WI) and the antisense RNA was synthesized using $T_{7}$ RNA polymerase and $\left.{ }^{32} \mathrm{P}\right] \mathrm{GTP}(410 \mathrm{Ci} / \mathrm{mmol}$, sp act) as described by the manufacturer. The labeled RNA was separated from unincorporated GTP by G-50 
Sephadex chromatography. Hybridization to the RNA probe was carried out at $65^{\circ} \mathrm{C}$ in the same hybridization solution as described above except that the formamide concentration was varied from 50 to $35 \%$. Filters were washed in $0.1 \times \mathrm{SSPE}$ at $65^{\circ} \mathrm{C}$ (three washes of $30 \mathrm{~min}$ each) followed by autoradiography.

\section{Results}

Probing Northern blots of polyadenylated (Fig. 1) or total (Fig. 2) Hep-G2 RNA under stringent conditions with full-length HepG2 glucose transporter cDNA yielded a single 2.8-kilobase (kb) transcript. The same size, single 2.8 -kb transcript was detected in blots of total cellular RNA prepared from rat heart, fat, brain, and liver (Fig. 1). When normalized to the amount of total cellular RNA added, message abundance was comparable in rat heart and fat RNA, and was 5-10-fold greater in brain RNA. The strong signal in brain appears to be in part a result of a very abundant transporter mRNA in brain microvessels (Fig. 3). Thus, when similar amounts of RNA from calf brain cortex and microvessels derived from this cortex are probed on Northern blots, the 2.8-kb transporter mRNA is much more abundant in vessels than in whole cortex.

Surprisingly, and in sharp contrast to the finding with HepG2 human hepatoma cells, there was very little hybridization of this probe to total RNA isolated from normal rat liver (Fig. 1). Liver RNA displayed only $2-5 \%$ relative abundance of this transcript compared with fat or heart RNA. When polyadenylated RNA from rat liver or isolated rat hepatocytes was probed, however, a definite 2.8-kb signal was observed, indicating that there is some expression of a highly homologous or identical mRNA species in hepatocytes (Fig. 3). The minimal expression of this mRNA species in normal adult rat and human liver, as

HEP G2 HEART FAT BRAIN LIVER

$20 \mu g \quad 7 \mu g \quad 20 \mu g \quad 30 \mu g$

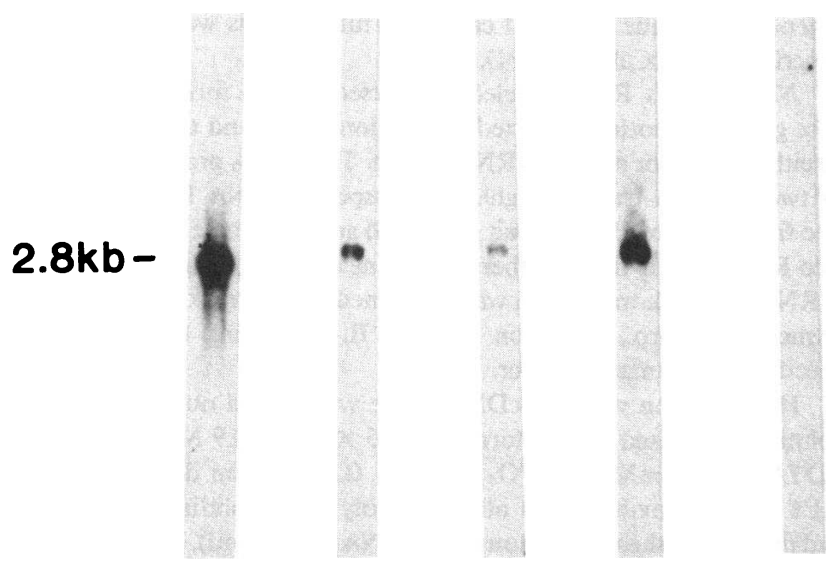

Figure 1. Detection of glucose transporter mRNA in hepatocyte (HEP) G2 cells and rat tissues by Northern gel blot analysis using the cDNA probe as described in Methods. The Hep-G2 lane contained 1 $\mu \mathrm{g}$ of polyadenylated RNA, and rat tissue lanes contained the indicated amount of total cellular RNA. The autoradiogram was exposed for $18 \mathrm{~h}$ at $-70^{\circ} \mathrm{C}$. This experiment is representative of three additional experiments, each of which used independently extracted RNA from different animals. opposed to Hep G2 hepatoma cells, raised the possibility that expression of the transporter mRNA might be greater in fetal liver cells. However, when RNA from fetal and neonatal rat liver was probed on Northern blots with the Hep G2 glucose transporter cDNA, there was little or no hybridization signal at high stringency, just as was seen in adult liver (Fig. 3).

Several human tissues were also available for study. As with rat RNA, the Hep-G2 cDNA probe detected a very weak 2.8$\mathrm{kb}$ signal when a large amount of normal human liver RNA was analyzed by Northern blotting (Fig. 2). In contrast, Hep-G2 cells, cultured skin fibroblasts, and EB virus-transformed lymphocytes contained an abundant 2.8-kb RNA species that hybridized with the cDNA probe (Fig. 2). Normal human muscle was not available for study, but leg muscle from two patients with type II diabetes was available. The same size $2.8-\mathrm{kb}$ transcript was seen at high stringency in RNA from both of these (Fig. 2).

To further investigate the finding that RNA from normal rat and human liver hybridized weakly to the Hep-G2 cDNA probe, we prepared a ${ }^{32} \mathrm{P}$-labeled antisense RNA and used this to probe Northern blots of polyadenylated RNA from rat and human liver and rat adipocytes at varying hybridization stringencies (data not shown). At high stringency of hybridization $\left(50 \%\right.$ formamide, $\left.65^{\circ} \mathrm{C}\right)$ and washing $\left(0.1 \times \mathrm{SSPE}, 65^{\circ} \mathrm{C}\right)$ a single 2.8-kb transcript was detected in all samples, and the relative abundance was consistent with previous studies using a cDNA probe. When hybridization stringency was reduced moderately by decreasing the formamide concentration from 50 to $35 \%$, a number of new transcripts were detected in normal human liver RNA. These were both larger and smaller than the 2.8-kb transcript, and their combined intensity exceeded that of the $2.8-\mathrm{kb}$ transcript.

\section{Discussion}

We have used the glucose transporter cDNA from Hep-G2 human hepatoma cells to assess the expression of homologous glucose transporter mRNA species in various rat and human tissues, and have made several significant observations. First, there is likely to be considerable sequence homology between the rat and human glucose transporters since mRNA transcripts of the same size and abundance are detected in tissues of these two species under stringent hybridization conditions using the human cDNA probe. ${ }^{1}$ Previous data on the apparent molecular size of the transporter $(13,14)$, as well as on the affinity of the transporter for both cytochalasin $B(15,16)$ and anti-transporter antibodies (17) are also consistent with close similarity between the human and rat transporters. Second, different tissues express markedly different levels of glucose transporter mRNA. Of the tissues that we have examined, rat brain has the greatest abundance. This may not be surprising, given the well-known fact that the central nervous system is highly dependent upon a continuous supply of glucose to meet its metabolic needs (18). Among the adaptations that have developed is a very high rate of glucose extraction by the brain, a process that appears to involve a high rate of glucose transport across the blood-brain barrier (19). Consistent with these facts, our studies have revealed that the

1. Since submission of this manuscript, the rat brain transporter cDNA has been cloned and sequenced, and a $97 \%$ homology at the protein level between the rat brain and human Hep G2 transporters has been reported (20). 


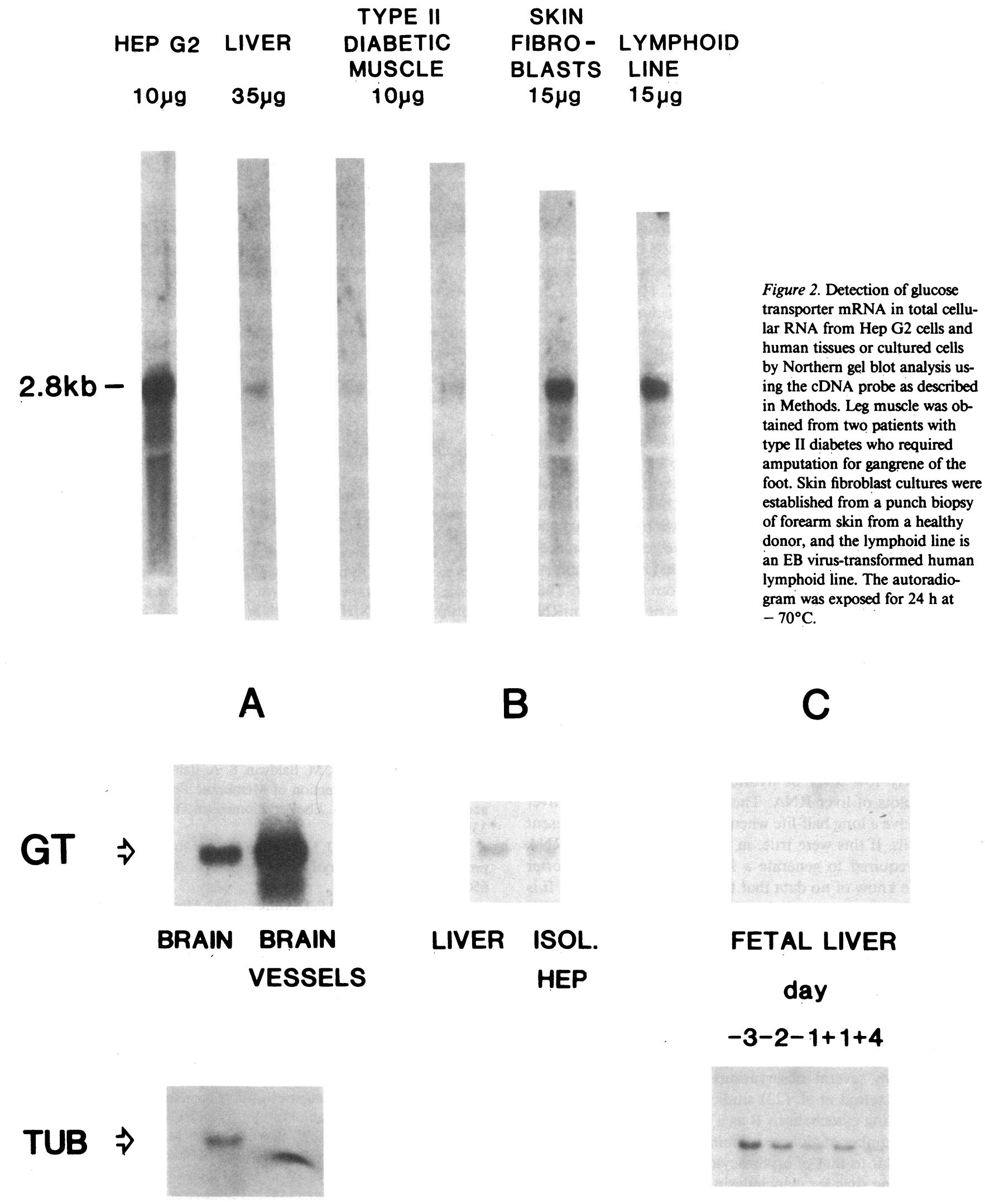

Figure 3. Detection of glucose transporter mRNA in various tissues by Northern gel blot analysis using cDNA or cRNA probes as described in Methods. In $A$, total cellular RNA from whole calf brain $(27 \mu \mathrm{g})$ or calf brain microvessels $(12 \mu \mathrm{g})$ was probed with either glucose transporter cDNA (i.e., GT) or rat tubulin cDNA (TUB). The GT autora-

diogram was exposed for $4 \mathrm{~h}$ and TUB was exposed for $1 \mathrm{~h}$. In $B$, rat liver $(5 \mu \mathrm{g})$ or isolated (ISOL.) rat hepatocyte (HEP) (4 $\mu \mathrm{g})$ polyadenylated RNA was probed with the glucose transporter cRNA. Exposure was for $70 \mathrm{~h}$. In $C, 16-21-\mathrm{d}$ fetal liver RNA $(22 \mu \mathrm{g})$ was probed with either GT (72-h exposure) or TUB (2-h exposure) cDNA. 
abundance of glucose transporter mRNA is severalfold higher in brain microvessels than in extracts of whole brain.

After the brain, the primary tissues with the greatest abundance of glucose transporter mRNA transcripts appear to be fat and muscle. These two tissues are important for in vivo glucose homeostasis and their glucose transport systems are well known to be sensitive to insulin. That a highly homologous transporter mRNA species is present in erythrocytes, where transport is insensitive to insulin, and in fat and muscle, where transport is insulin sensitive, suggests that the insulin-responsive transporter is similar, if not identical, to the insulin-insensitive erythrocyte transporter. This would imply the existence of an additional molecular component that would be responsible for conferring insulin sensitivity to the transport process. However, the fact that hybridization to the same size mRNA occurs under stringent conditions does not itself constitute proof that the mRNA species encoding glucose transporters in insulin-sensitive and -insensitive tissues are identical. $S_{1}$ nuclease protection studies and/or cloning and sequencing of the transporter cDNAs from each tissue would be necessary for definitive information on this subject.

The extremely low abundance of mRNA in normal rat and human liver that is capable of hybridizing to the Hep-G2 glucose transporter cDNA probe raises a number of questions. Could it be that the observed weak signal reflects RNA from cells other than hepatocytes that make up $10 \%$ of the liver mass, as suggested by Birnbaum et al. (20)? This reasonable suggestion is unlikely, given our observation that RNA from isolated hepatocytes gives a signal as strong as that seen with RNA from total liver. Thus, hepatocytes do appear to have a homologous or identical mRNA species. Why is the abundance of this mRNA so low? Previous studies on intact liver (21) and on isolated hepatocytes (22) reveal that hepatocytes have a very active glucose-facilitated uptake system that is similar in magnitude to that of the erythrocyte (when normalized to cellular water space).

At least three explanations could account for the apparent discordance between the abundance of glucose transport and the relatively low level of hybridizable mRNA detected by Northern blots of liver RNA. The glucose transporter of liver cells may have a long half-life when compared with that present in other cells. If this were true, in the steady state less mRNA would be required to generate a fixed amount of transporter protein. We know of no data that bears on this possibility. It is also possible that the translational efficiency of the transporter message is very high in liver cells; this supposition also lacks experimental support. A third possibility, which we currently favor, is that hepatocytes contain an additional glucose transporter that is encoded by a homologous but distinct mRNA species. This possibility is consistent with the appearance of several additional bands on Northern blots of liver poly A RNA when hybridization stringency is modestly reduced. It is also consistent with several observations on the hepatic glucose transporter. Axelrod et al. (23) studied the rat hepatic glucose transporter using cytochalasin $B$ as a probe and observed that, whereas the number of glucose inhibitable cytochalasin binding sites was similar to that of erythrocyte membranes, the affinity of these binding sites for cytochalasin was 10-fold less in hepatocyte membranes than in erythrocyte membranes. As suggested by these workers, this could reflect the existence of structurally distinct transporter species in these two tissues. In further support of this possibility is the observation (Cushman, S. W., personal communication) that antibodies against the erythrocyte glucose transporter that recognize putative transporters in adipocytes on
Western blots only very weakly recognize a hepatic glucose transporter species. Ultimately, validation of this concept will depend entirely upon the cloning and sequencing of a unique transporter cDNA from hepatocytes, and attempts at this are currently in progress in our laboratories.

The final question relates to the meaning of the marked differences in expression of the Hep-G2 glucose transporter message in normal liver as opposed to Hep-G2 cells, which are clearly hepatocytic in origin and which express a wide variety of differentiated functions characteristic of hepatocytes (24). It has long been known that transformed cells or primary tumors often display increased rates of glucose uptake and metabolism (25), although the molecular mechanism by which these changes come about have been obscure. We suspect the increased abundance of glucose transporter-specific mRNA in Hep-G2 cells is an example of such a transformation-related phenomenon, and our observation may represent the first indication that the molecular mechanism for such an increase in transport is an increase in the steady state level of glucose transporter mRNA.

\section{Acknowledgments}

We would like to thank Dr. Motozumi Okamoto for making available the isolated rat hepatocytes and Terri Wiseman for aid in preparing the manuscript.

Dr. Flier is the recipient of a Research Career Development Award from the National Institutes of Health (NIH). This work was supported in part from grants AM-28082 (to Dr. Flier) and GM-35012 (to Dr. Lodish) from the NIH, and by U. S. Public Health Service grants PO1-HL-26895 and 5-R01-NS22213 (to Dr. McCall).

\section{References}

1. Wheeler, T. J., and P. C. Hinkle. 1985. The glucose transporter of mammalian cells. Ann. Rev. Physiol. 47:503-5i7.

2. Lienhard, G. E., J. M. Baldwin, S. A. Baldwin, and F. R. Gorga. 1983. Structure and Function of Membrane Proteins. E. Quagliarello and F. Palmieri, editors. Elsevier Biomedical Press, Amsterdam. 325333.

3. Jones, M. N., and J. K. Nickson. 1981. Monosaccharide transport proteins of the human erythrocyte membrane. Biochem. Biophys. Acta. 650:1-39.

4. Wheeler, T. J., and P. C. Hinkle. 1982. Membranes and Transport. A. N. Martonosi, editor. Plenum Publishing Corp., New York. 161-167.

5. Mueckler, M. M., C. Caruso, S. A. Baldwin, M. Panico, I. Blench, H. R. Morris, J. W. Allard, G. E. Lienhard, and H. F. Lodish. 1985. Sequence and structure of a human glucose transporter. Science (Wash. DC). 229:941-945.

6. Wardzala, L. J., and B. Jeanrenaud. 1981. Potential mechanism of insulin action on glucose transport in isolated rat diaphragm. J. Biol. Chem. 256:7090-7093.

7. Crofford, O. B., and A. E. Renold. 1965. Glucose uptake by incubated rat epididymal adipose tissue. Characteristics of the glucose transport system and action of insulin. J. Biol. Chem. 240:3237-3244.

8. Chirgwin, J. M., A. W. Przybyla, R. J. MacDonald, and W. J. Rutter. 1979. Isolation of biologically active ribonucleic acid from sources enriched in ribonuclease. Biochemistry. 18:5294-5299.

9. Aviv, H., and P. Leder. 1972. Purification of biologically active globin messenger RNA by chromatography on oligothymidylate acidcellulase. Proc. Natl. Acad. Sci. USA. 69:1408-1412.

10. Okamoto, M., M. F. White, R. Maron, and C. R. Kahn. 1986. Autophosphorylation and kinase activity of insulin receptor in diabetic rats. Am. J. Physiol. 14:E542-E550.

11. McCall, A. L., J. B. Gould, and N. B. Ruderman. 1984. Diabetes 
induced alterations of glucose metabolism in cerebral microvessel. $\mathrm{Am}$. J. Physiol. 247:E462-E467.

12. Maniatis, T., E. F. Frisch, and J. Sambrook. 1982. Molecular Cloning: A Laboratory Manual. Cold Spring Harbor Laboratory, New York. 202-203.

13. Carter-Su, C., J. E. Pessin, R. Mora, W. Gitomer, and M. P. Czech. 1982. Photoaffinity labelling of the human erythrocyte D-glucose transporter. J. Biol. Chem. 257:5419-5425.

14. Wheeler, T. J., I. A. Simpson, D. C. Sogin, P. C. Hinkle, and S. W. Cushman. 1982. Detection of the rat adipose cell glucose transporter with antibody against the human red cell glucose transporter. Biochem. Biophys. Res. Commun. 105:89-95.

15. Jung, C. J., and A. L. Rampol. 1977. Cytochalasin B binding sites and glucose transport carrier in human erythrocyte ghosts. J. Biol. Chem. 252:5456-5463.

16. Wardzala, L. J., S. W. Cushman, and L. B. Salans. 1978. Mechanism of insulin action on glucose transport in the isolated rat adipose cell. J. Biol. Chem. 253:8002-8005.

17. Allard, W. J., and G. E. Lienhard. 1985. Monoclonal antibodies to the glucose transporter from human erythrocytes. J. Biol. Chem. 260: 3668-3674.

18. Sokoloff, L., G. G. Fitzgerald, and E. E. Kaufman. 1977. Nutrition and the Brain. R. J. Wurtman and J. J. Wurtman, editors. Raven Press, New York. 87-139.

19. Pardridge, W. M., and W. H. Oldendorf. 1977. Transport of metabolic substrates through the blood:brain barrier. J. Neurochem. 28: $5-12$.

20. Birnbaum, M. J., H. C. Haspel, and O. M. Rosen. 1986. Cloning and characterization of a cDNA encoding the rat brain glucose transporter protein. Proc. Natl. Acad. Sci. USA. 83:5784-5788.

21. Williams, T. F., J. H. Exton, C. R. Park, and D. M. Regen. 1968. Stereospecific transport of glucose in the perfused rat liver. Am. J. Physiol. 215:1200-1209.

22. Craik, J. D., and K. R. F. Elliott. 1979. Kinetics of 30 methyl glucose transport in isolated rat hepatocytes. Biochem. J. 182: 503-508.

23. Axelrod, J. D., and P. F. Pilch. 1983. Unique cytochalasin B binding characteristics of the hepatic glucose carrier. Biochemistry. 22: 2222-2227.

24. Knowles, B. B., C. C. Howe, and D. P. Aden. 1980. Human hepatocellular carcinoma cell lines secrete the major plasma proteins and hepatitis B surface antigen. Science (Wash. DC). 209:497-499.

25. Salter, D. W., and M. J. Weber. 1979. Glucose specific cytochalasin B binding is increased in chicken embryo fibroblasts transformed by Rous sarcoma virus. J. Biol. Chem. 254:3554-3561. 